\title{
AFFORDABLE POLYMER COMPOSITE STRUCTURES FOR VARIOUS SPACECRAFT STRUCTURAL COMPONENTS
}

\author{
G. C. Krumweide, Director of Program Development \\ Composite Optics, Incorporated \\ San Diego, California
}

\begin{abstract}
The purpose of this technical paper is to inform spacecraft structural designers that recent developments in Polymer Matrix Composite (PMC) materials have the potential to displace most aluminum materials in structures. This paper reports on recent advances and applications of PMC materials technologies and how these technologies provide affordable structures, produced in less time, while satisfying structural performance requirements. Moreover, these advances in PMC materials and their application will allow "leap ahead" advances in spacecraft technology. In some structural applications, near order-of-magnitude differences in structural component cost may be possible because the advanced PMC design and manufacturing approach lends itself to automation. Current examples of polymer matrix composites spacecraft structure developed (or being developed) by Composite Optics, Incorporated will be briefly discussed.
\end{abstract}

\section{INTRODUCTION}

All subsystems on board a spacecraft need some type of structure for support, environmental protection or some other, functional purpose. For instance, a power subsystem needs a substrate to support the array of solar cells; an electrical subsystem needs a board (PWB) for its electronics and/or circuitry, and a housing to support the board(s), and maybe even a deck to mount

the housing. And, of course, all subsystems need a payload or bus structure. All of these structural components are functionally important to spacecraft subsystems and, clearly, the materials selected for their fabrication will be critical to their successful performance, and a key to the overall cost/benefit payoffs for that spacecraft.

From the very beginning of the Space Program, the primary material of choice has been aluminum or aluminum honeycomb sandwich for spacecraft and subsystem structures and components. The benefits of aluminum were evident: lightweight, inexpensive, readily available, easily manufactured, reliable, and most importantly, designers were familiar with its properties and how to apply them. Only when some unique material property was necessary did invar, beryllium or fiberglass find application in certain spacecraft components. However, over time, polymer matrix composites have slowly replaced aluminum in general, as well as replacing invar and beryllium in specialized applications.

Understandably, the "exotic" material label given to polymer matrix composites (PMC) previously kept the designers of various spacecraft structure components from employing the material--that, and high cost. High cost meant that only high performance pay-off structures were targeted for initial applications of composites. Structures, such as reflector dishes and optical benches qualified as "high performance pay-off" structures. Solar array substrates for spacecraft power systems followed next. 
It is interesting to note, that even for these high performance pay-off applications, there still is not a complete conversion to PMC structures.

Most likely "old paradigms" account for this-that is, PMCs are still thought of as "exotic" and believed to be too costly and designers are unaware of major property improvements.

But PMC technology is starting to "leap ahead" and it is the purpose of this paper to inform designers of these technological advancements. The "exotic" connotation is no longer appropriate when hundreds of PMC reflectors, solar array substrates, and optically stable structures are, or have been, functioning successfully on-orbit.

This is being made possible by several significant technological developments, namely; new low outgassing materials, high modulus and highly conductive polymer composites, and affordable design and manufacturing methods.

Of primary importance is that these new technologies can make PMC spacecraft structures nearly as affordable as aluminum structures (or metallic structures, in general), and not just because of the hurl weight cost savings or high performance pay-off. Soon the only difference in spacecraft costs may well be raw materials (i.e., the cost of aluminum sheet or plate versus polymer matrix composite prepreg).

To characterize these "leap ahead" technologies towards affordable spacecraft structural components, this paper will discuss the following three topics.

\section{Polvmer Matrix Composites}

For these materials, the enabling technologies to be described are the low moisture absorbing poly-cyanate ester resins, the highly conductive "pitch fiber" composite, and high strength and modulus "pan fiber" composites.
Design and Manufacturing

The importance of CAD/CAM will be described along with the emerging new flat laminate construction methods that minimize tooling through use of self-fixturing techniques, and "automation" of the manufacturing process.

\section{Recent Technology Applications}

Some affordable spacecraft structural components are:

- Los Alamos FORTÉ all composite spacecraft bus structure (Flight Qual complete).

- New PMC electronic housing (cardcage) concepts, one of which was thermal vacuum tested by Sandia National Lab and compared with a typical aluminum electronic cardcage.

- New PMC isogrid concept that may offer significant advantages over aluminum and composite honeycomb sandwich for many structural components (i.e., Bus, SAS, solar concentrators, etc.).

- A possible approach to multi-functional structures where an optical bench, electronic housing, radiators, bus, etc. are combined into one integrated structure.

\section{DISCUSSION}

Technology Advancement Utilizing PMC Material

Composite Optics, Incorporated, as a manufacturer of hardware for many space satellite projects, whether for science, defense or commercial purposes, has characterized a number of Polymer Matrix Composite (PMC) materials over the years. The capability of PMC materials to satisfy many earlier design challenges has greatly improved in recent years; "and has fostered technology advances toward affordable spacecraft structural components.

Listed below are some of the earlier PMC material characteristics that various design 
"workaround" techniques had to be overcome".

Anisotropic Behavior

Highly Hygroscopic Nature

Susceptibility to Microcracking

Susceptibility to Impact Damage

Low Peel Strengths

Material Cost

Fabrication Cost

Recent advancements in resins, fibers and the prepreg itself have eliminated the previous needs to "workaround" PMC material undesirable characteristics.

\section{Resin Development}

The most significant PMC material development in the last five years has been the introduction of the poly-cyanate ester resin systems.

Two of the primary poly-cyanate ester (or cyanate) resins that $\mathrm{COI}$ has characterized and currently utilize are: Fiberite's $954-3$ and YLA's RS-3. These materials have served to potentially:

1. Reduce outgassing by a factor of 3 (compared to epoxies)

2. Reduce dimensional distortion of a stable structures (due to moisture ingress and egress) by a factor of 3

3. Allow service temperature to increase by $100-250^{\circ} \mathrm{F}$ (increased $\mathrm{Tg}$ )

4. Virtually eliminate microcracking in PMC laminates so long as the cure ply thickness is not large (i.e., <0.005)

5. Facilitate the platability of PMC laminates
These improvements have occurred without significant changes in mechanical properties when compared with earlier epoxy and modified epoxy systems ${ }^{2}$. For optical structures and electronic packaging, these improvements over epoxy systems are of utmost importance.

\section{Fiber Developments}

Pan fibers, such as moderately priced M55J or highly priced M60J made by Toray) can allow for very efficient structures because their specific strengths and modulus are 2 and 2.5 times, respectively, greater than aluminum. These fibers also have fiber tensile moduli 2 and 3 times greater than the old standby fibers such as T-50 and T300, respectively.

Pitch fibers such as Amoco's P120, Mitsubishi's K13C2U and Amoco's K1100X have laminate thermal conductivities $(\mathrm{K})$ equal to, or $60 \%$ greater, than aluminum. That is, an isotropic laminate of $\mathrm{P} 120$ and $\mathrm{K} 13 \mathrm{C} 2 \mathrm{U}$ is $160 \mathrm{~W} / \mathrm{m}^{\circ} \mathrm{K}$ and $\mathrm{K} 1100 \mathrm{X}$ is approximately 300 $\mathrm{W} / \mathrm{m}^{\circ} \mathrm{K}$ where typically aluminum is 160 $\mathrm{W} / \mathrm{m}^{\circ} \mathrm{K}$. For electronic packaging applications, these thermal conductivity property improvements enable the use of PMC materials for applications, that just a few years ago, were not possible.

\section{PMC Development}

Interestingly enough, by using these high conductivity materials in combination with high strength pan fiber and cyanate resins, the number of PMC applications has expanded greatly; namely: avionics, photovoltaic panels, phased arrays, phase charge devices, heatpipes, etc. $^{3}$ More detail is provided later. 
Affordable Structures Utilizing Advanced Design/Manufacturing Methods

Affordability is the "word" in vogue today because of the prior overuse of "low cost". Also, low cost has no universal reference. That is, today's buyer, generally speaking, will not buy low cost hardware if it does not fit the budget.

The implications are clear, that in the future if PMC structural components are to displace aluminum structural components for spacecraft, they have to be reasonably near the same cost and be equal, or superior, to the aluminum structural components performance.

There are many spacecraft applications for PMC materials as seen in Table 1. Likewise in Table 2, it can be seen that after considering the critical requirements associated with some of these applications, PMC materials can satisfy most spacecraft requirements. Today, this is especially true because design and manufacturing methods have the potential to reduce costs nearly an order-of-magnitude.

For many of these applications, "old paradigms" are preventing "leap ahead" or affordable technologies from being implemented, namely:

"Better to co-cure structures because secondary bonding is too risky."

"Better to co-cure to reduce part count because the more parts, the more it costs."

From a system or subsystem point of view, reduction of the number of parts will certainly reduce cost. But when parts are "Group Part Processed"TM as for instance, in a model airplane kit where all parts in a sheet are handled as one part, this may not be true. Primarily, because other than "planar" shape, all parts are exactly alike; are processed together and assembled into a single structural component.

\section{Table 1 PMC Applications for Spacecraft Structures}

\section{Equipment Structures}

Reflectors

Feed Horns and Waveguide Assemblies

MUX Cavities

Diplexers

Phased Arrays

Large Segmented Solar Collectors

Solar Array Substrates (or Photovoltaic Panels)

Heatpipes (or Phase Change Devices)

Booms

Bus/Payload Structures (Frames, Panels, Decks)

Electronic Housings/Cardguides

Thermal Cores/PWB Heatsinks

\section{Instrument Structures}

Metering Structures/Telescopes

Camera Housings

Optical Benches

Mirror Bezel

Mirrors

Support Benches 
Table 2 Material Selection Criteria

\begin{tabular}{|c|c|c|c|c|c|c|}
\hline \multirow{2}{*}{$\begin{array}{c}\text { CRITICAL } \\
\text { REQUIREMENTS }\end{array}$} & \multicolumn{6}{|c|}{ SPACECRAFT APPLICATION } \\
\hline & RF Reflectors & $\begin{array}{l}\text { Solar Panel } \\
\text { Substrates }\end{array}$ & $\begin{array}{c}\text { BUS } \\
\text { Structures }\end{array}$ & $\begin{array}{l}\text { Electronic } \\
\text { Housings }\end{array}$ & $\begin{array}{l}\text { Stable } \\
\text { Structures }\end{array}$ & Mirrors \\
\hline MASS & $\begin{array}{l}\text { PMC (1) } \\
\text { Kevlare }\end{array}$ & $\begin{array}{l}\text { PMC (1) } \\
\text { Kevlar@ }\end{array}$ & $\begin{array}{l}\text { PMC } \\
\text { Aluminum } \\
\mathrm{M} / \mathrm{M}\end{array}$ & $\begin{array}{c}\text { PMC } \\
\text { Aluminum } \\
\text { Beryllium } \\
\mathrm{M} / \mathrm{M}\end{array}$ & $\begin{array}{l}\text { PMC (5) } \\
\text { Beryllium }\end{array}$ & $\begin{array}{l}\text { PMC (6) } \\
\text { Beryllium } \\
\text { Si/C } \\
\text { C/C }\end{array}$ \\
\hline $\begin{array}{l}\text { DYNAMIC } \\
\text { STABILITY }\end{array}$ & $\begin{array}{l}\text { PMC (1) } \\
\text { Kevlare }\end{array}$ & $\begin{array}{l}\text { PMC (1) } \\
\text { Kevlare } \\
\text { Aluminum }\end{array}$ & $\begin{array}{l}\text { PMC } \\
\text { Aluminum } \\
\mathrm{M} / \mathrm{M}\end{array}$ & $\begin{array}{l}\text { PMC } \\
\text { Aluminum } \\
\text { Beryllium } \\
\text { MMM }\end{array}$ & $\begin{array}{l}\text { PMC (5). } \\
\text { Beryllium } \\
\text { Invar }\end{array}$ & $\begin{array}{l}\text { PMC (6) } \\
\text { Beryllium } \\
\text { Si/C, C/C } \\
\text { Aluminum }\end{array}$ \\
\hline $\begin{array}{l}\text { THERMAL } \\
\text { STABILITY }\end{array}$ & PMC & $\begin{array}{l}\text { PMC (1) } \\
\text { Kevlare }\end{array}$ & $\begin{array}{l}\text { PMC (5) } \\
\text { Invar }\end{array}$ & $\begin{array}{c}\text { PMC } \\
\text { Beryllium } \\
{\mathrm{M} / \mathrm{M}^{\circ}}^{\circ}\end{array}$ & $\begin{array}{l}\text { PMC (5) } \\
\text { Invar } \\
\text { Beryllium }\end{array}$ & $\begin{array}{l}\text { PMC (6) } \\
\text { Invar } \\
\text { Beryllium } \\
\mathrm{Si} / \mathrm{C}, \mathrm{C} / \mathrm{C} \\
\end{array}$ \\
\hline $\begin{array}{l}\text { DYNAMIC } \\
\text { LOADS (G's) }\end{array}$ & $\begin{array}{l}\text { PMC (1) } \\
\text { Kevlare }\end{array}$ & $\begin{array}{l}\text { PMC (1) } \\
\text { Kevlar@ } \\
\text { Aluminum }\end{array}$ & $\begin{array}{c}\mathrm{PMC} \\
\text { Aluminun } \\
\mathrm{M} / \mathrm{M}\end{array}$ & $\begin{array}{c}\text { PMC } \\
\text { Beryllium } \\
\text { M/M } \\
\text { Aluminum }\end{array}$ & $\begin{array}{l}\text { PMC (5) } \\
\text { Beryllium } \\
\text { Invar }\end{array}$ & $\begin{array}{l}\text { PMC (6) } \\
\text { Invar } \\
\text { Beryllium } \\
\text { Aluminum } \\
\end{array}$ \\
\hline $\begin{array}{l}\text { TEMPERATURE } \\
\text { EXTREMES }\end{array}$ & $\begin{array}{l}\text { PMC (2) } \\
\text { Kevlar@ }\end{array}$ & $\begin{array}{l}\text { PMC (2) } \\
\text { Kevlar® } \\
\text { Aluminum }\end{array}$ & $\begin{array}{l}\text { PMC (2) } \\
\text { Aluminum } \\
\mathrm{M} / \mathrm{M}\end{array}$ & $\begin{array}{c}\text { PMC (2) } \\
\text { Beryllium } \\
\text { MMM } \\
\text { Aluminum }\end{array}$ & $\begin{array}{l}\text { PMC (2) } \\
\text { Invar } \\
\text { Beryllium }\end{array}$ & $\begin{array}{l}\mathrm{PMC}(2)(6) \\
\mathrm{Si} / \mathrm{C}, \mathrm{C} / \mathrm{C} \\
\text { Beryilium } \\
\text { Aluminum }\end{array}$ \\
\hline HYGROSTABILITY & $\operatorname{PMC}(2)$ & $\begin{array}{l}\text { PMC (2) } \\
\text { Aluminum }\end{array}$ & $\begin{array}{l}\text { PMC (2) } \\
\text { Aluminum } \\
\text { M/M }\end{array}$ & $\begin{array}{l}\text { PMC (2) } \\
\text { Beryllium } \\
\text { M/M } \\
\text { Aluminum }\end{array}$ & $\begin{array}{l}\text { PMC (2) } \\
\text { Beryllium } \\
\text { Invar }\end{array}$ & $\begin{array}{c}\text { PMC (2)(6) } \\
\text { Invar } \\
\text { Beryllium } \\
\text { Aluminum } \\
\mathrm{Si} / \mathrm{C}, \mathrm{C} / \mathrm{C}\end{array}$ \\
\hline $\begin{array}{l}\text { HIGH THERMAL } \\
\text { CONDUCTIVTTY }\end{array}$ & PMC (3) & $\begin{array}{l}\text { PMC (3) } \\
\text { Aluminum }\end{array}$ & $\begin{array}{l}\mathrm{PMC}(3) \\
\text { Aluminum } \\
\mathrm{M} / \mathrm{M}\end{array}$ & $\begin{array}{c}\text { PMC (3) } \\
\text { Beryllium } \\
\text { M/M } \\
\text { Aluminum }\end{array}$ & $\begin{array}{l}\text { PMC (3) } \\
\text { Beryllium } \\
\text { Invar }\end{array}$ & $\begin{array}{c}\text { PMC (3)(6) } \\
\text { Invar } \\
\text { Beryllium } \\
\text { Aluminum } \\
\mathrm{Si} / \mathrm{C}, \mathrm{ClC} \\
\end{array}$ \\
\hline $\begin{array}{l}\text { LOW THERMAL } \\
\text { CONDUCTTVITY }\end{array}$ & PMC (4) & $\begin{array}{l}\text { PMC (4) } \\
\text { Kevlare }\end{array}$ & $\mathrm{PMC}(4)$ & PMC (4) & $\operatorname{PMC}(4)$ & $\operatorname{PMC}(4)(6)$ \\
\hline $\begin{array}{l}\text { RF } \\
\text { TRANSMISSIBILITY }\end{array}$ & Kevlar@ & Kevlar@ & - & - & - & - \\
\hline $\operatorname{cosT}$ & $\begin{array}{c}\text { PMC } \\
\text { Kevlar® }\end{array}$ & $\begin{array}{l}\text { PMC (1) } \\
\text { Kevlar@ } \\
\text { Aluminum }\end{array}$ & $\begin{array}{c}\text { PMC } \\
\text { Aluminum }\end{array}$ & $\begin{array}{l}\text { PMC } \\
\text { Aluminum }\end{array}$ & $\begin{array}{l}\text { PMC } \\
\text { Invar }\end{array}$ & $\begin{array}{l}\text { Aluminum } \\
\text { Invar }\end{array}$ \\
\hline
\end{tabular}

(1) Combinations of Kevlar \& PMC is used when mass and dynamic stability is important.

(2) Cyanate Resins have been shown to handle temperature extremes (higl glass transition temperature, $\mathrm{Tg}$, no microcracking, low outgassing).

(3) Pitch Fibers (especially ultra, ultra high modulus lave high thermal conductivity).

(4) Pan Fibers have low thernal conductivity.

(5) Metals shown may be applicable if a small size structure

(6) PMC has been used successfully as mirror substrates and for some submillimeter reflectors core and skin. 
What has enabled these paradigms to no longer represent many PMC hardware applications is affordable design and manufacturing methods such as SNAPSAT ${ }^{\text {rM }}$.

SNAPSAT ${ }^{\text {TM }}$ design and manufacturing methods were initially applied to the FORTÉ Bus Structure, at least in part. The basic design and manufacturing principles of SNAPSAT $^{\top M}$ can be applied to many other types of structures. These basic principles include:

- $\mathrm{CAD} / \mathrm{DAM}$ design/manufacturing methods

- Flat laminate construction

- Group Part Processing ${ }^{\text {TM* }}$ (advanced etch and prime bond preparation)

- Self-fixturing methods

- And adaptation of advance adhesive dispensing methods

Due to the proprietary methods associated with SNAPSAT ${ }^{T M}$, only limited information can be presented in this paper.

In the next section, some of the recent applications of SNAPSAT ${ }^{\text {MM }}$ design and manufacturing methods will help establish the value of this technology.

\section{RECENT TECHNOLOGY APPLICATIONS}

\section{Los Alamos FORTÉ}

This spacecraft bus structure was codeveloped by Los Alamos and Composite Optics, Incorporated as reported in a recent publication $^{4}$.

\footnotetext{
SNAPSAT (trademarked by Composite Optics, Incorporated), stands for Short Notice Accelerated Production Satellite. The structural methods are patent pending.

† FORTE, termed by Los Alamos National Laboraton: to mean Fast-On Orbit Recording of Transient Events.

‡ Group Part Processing is trademarked by COI.
}

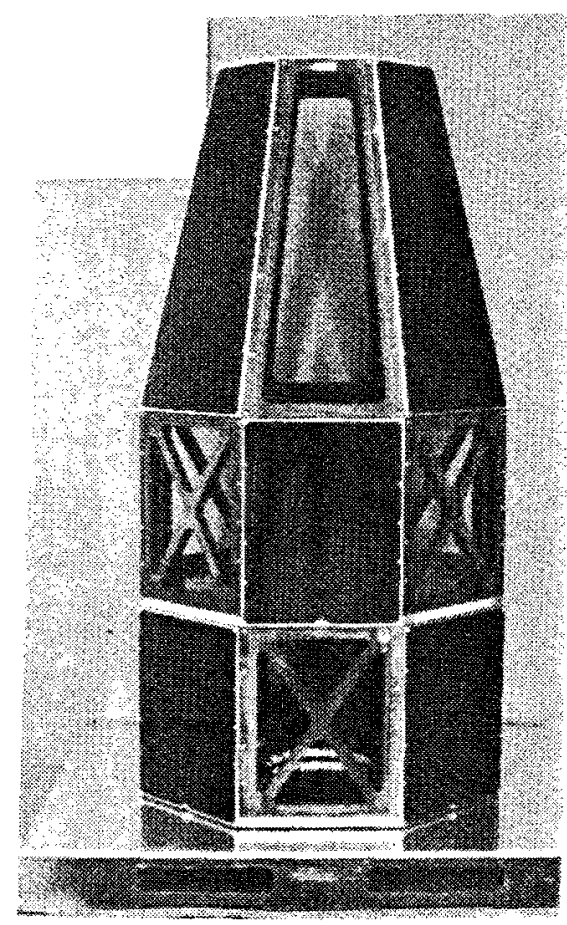

Figure 1 FORTÉ Bus Structure

Shown with only a few solar panels installed.

Figure 1 is a photograph of the FORTE PMC spacecraft bus structure which is basically a space frame constructed from "flat laminate panels," secondarily bonded together in such a manner that all truss members depicted are ' $\mathrm{I}$ ' beams. Eight ( 8 ) flat panel truss sides form the three space frames that make up this FORTE Bus Structural assembly. Honeycomb sandwich composed of PMC skins and aluminum honeycomb core provide the structure for the outer solar array substrates (SAS) panels and the three (3) equipment decks (lower, mid and upper). NOTE: Only some of the SAS panels are installed.

Figure 2 depicts the flat laminate panels that provide all the details making up the three (3) spaceframe assemblies. The upper panel in Figure 2 is actually four (4) panels stacked one on top of the other. The parts are Group Part Processed $^{T M}$ and then removed from the panels and assembly bonded using the SNAPSAT ${ }^{T M}$ self-fixturing approach. 

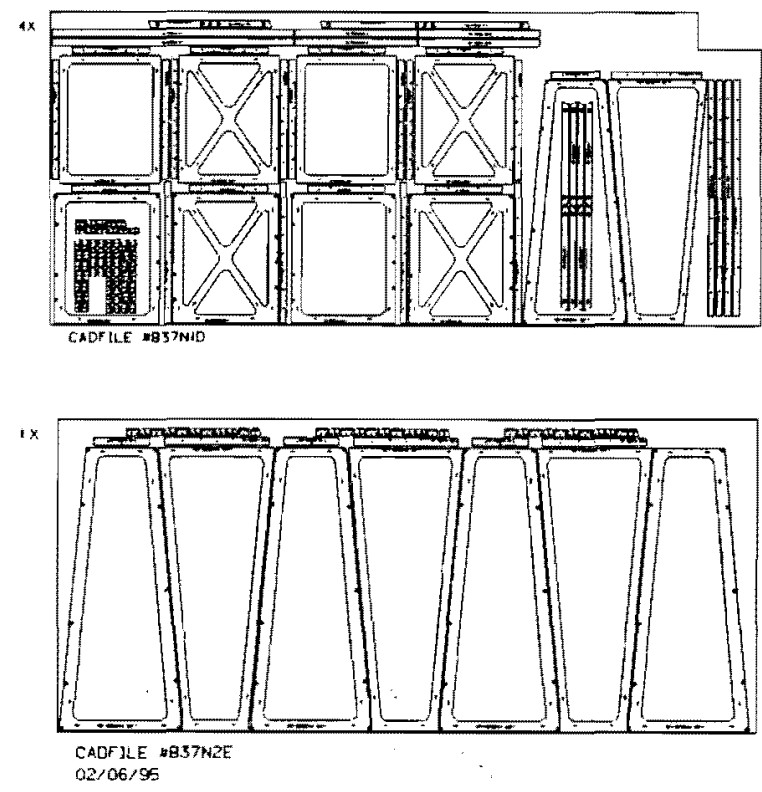

Figure 2 FORTÉ Bus Structure

Flat Laminate Panels that are Group Part Processed ${ }^{\text {TM }}$
Table 3 was presented by Los Alamos in a recent publication ${ }^{5}$. The significance of this table is the cost and schedule comparison between SNAPSAT ${ }^{\text {TM }}$ (or FORTÉ as designated in table), aluminum, and conventional PMC structures. The FORTÉ SNAPSAT ${ }^{T M}$ structure is only $40 \%$ of the cost of conventional composite structures, and only $23 \%$ greater in cost than aluminum structures. For a $48 \mathrm{lb}$. savings, that made the FORTÉ mission possible, this $23 \%$ cost increase is truly an insignificant amount.

The significance of schedule reduction in Table 3 is that the FORTÉ spacecraft bus structure was manufactured complete in ten weeks and in addition was more conducive to concurrent engineering efforts. That is, with less time needed for manufacturing, more time can be spent on the design and systems engineering effort.

Table 3 Manufacturing Comparison Matrix

\begin{tabular}{lccc} 
Parameter & FORTÉ Structure & $\begin{array}{c}\text { Aluminum Alloy } \\
\text { Structure }\end{array}$ & $\begin{array}{c}\text { Conventional } \\
\text { Composite Structure }\end{array}$ \\
\hline Material & Graphite/Epoxy & Aluninum & Graphite/Epoxy \\
Material Cost & High & Low & High \\
Material Advantage & Stiffness/Weight/Strength & Cost & Stiffness/Weight/Strength \\
Material Form & Flatstock panels & Metal Billet & Molded Parts \\
Manufacturing Process & Waterjet & Machining & Molding \\
Process Cost & Low & Moderate & High \\
Process Advantage & Quick turnaround time & Established Technology & Customized Technology \\
Fabrication Time & 10 weeks & 16 weeks & 30 weeks \\
Tooling Cost & Low &.- Low & High \\
Structure Weight & $42.6 \mathrm{Kg}(94 \mathrm{lb}$.) & $64.4 \mathrm{Kg}(142 \mathrm{lb})$. & $42.6 \mathrm{Kg}(94 \mathrm{lb}$.) \\
Unit Fabrication Cost & $\$ 160 \mathrm{~K}$ & $\$ 133 \mathrm{~K}$ & $\$ 400 \mathrm{~K}$
\end{tabular}


The two factors that allow the shortened schedule are minimal tooling (both design and fabrication) and flat laminates that are completed and ready for CAD/CAM prior to release of engineering drawings.

The current status of this FORTÉ PMC bus structure is that the engineering model has completed COI's qualification testing and the flight unit has been acceptance tested and delivered in these manufacturing span times. The qualification test included thermal cycling, static load testing (at COI) and sine/random vibration tests, EMI test and thermal vacuum testing (at LANL). All testing of the FORTÉ PMC structure was completed successfully.

\section{PMC Electronic Housings (Cardcage)}

The affordable SNAPSAT TM design manufacturing approach was also employed on an electronic cardcage not unlike that typically used on spacecraft; that is, with respect to geometry. The electronic cardcage was redesigned using mostly PMC materials in place of aluminum. Figure 3 is a photograph of the cardcage from a prior publication ${ }^{6}$. The fundamental design of this cardcage is patent pending, the details of its construction are still considered proprietary and cannot be detailed.

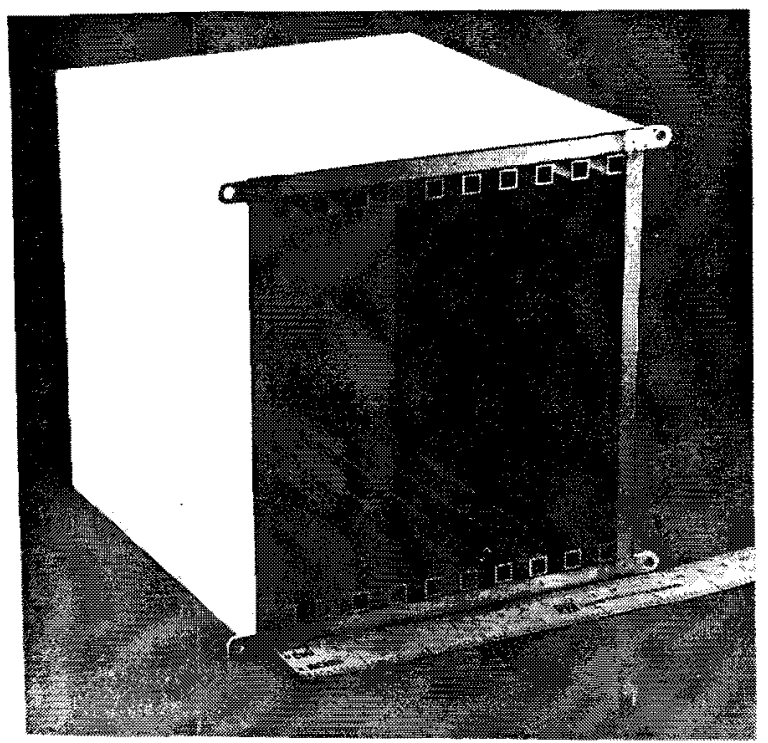

Figure 3
The effectiveness of this cardcage design to dissipate heat from the PWBs is summarized in Table 5. Figure 4 is a typical aluminum cardcage previously tested by Sandia National Laboratory. The PMC cardcage (Figure 3) was tested in the same test setup. The different configurations (3) of cardcages with clamped in G-10 PWBs are shown in Figures $4 a, 4 b, 4 c$. Figures $4 a$ and $4 c$ depict how the same G-10 PWB is clamped to the PMC cardcage and aluminum cardcage, respectively.

The important data point in Table 4 is the temperature at the center of the heat source on the PWB. The heat source temperature recorded a $20^{\circ} \mathrm{C}$ cooler reading for the $\mathrm{PMC}$ cardcage (as compared to the aluminum cardcage). Also important to note is that heat is thermally conducted away via the quarter-inch thick walls of the aluminum cardcage (Figure 4) to an aluminum vacuum chamber baseplate. The heat from the PMC cardcage was primarily dissipated through radiation (no attempt to thermally secure the PMC cardcage to the thermal vacuum chamber baseplate).

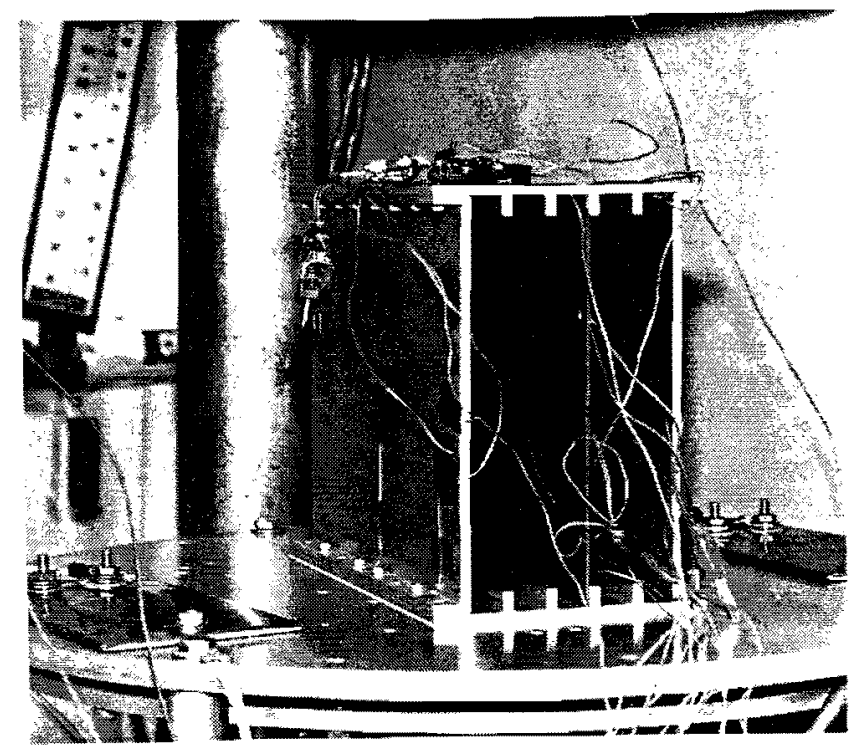

Figure 4 


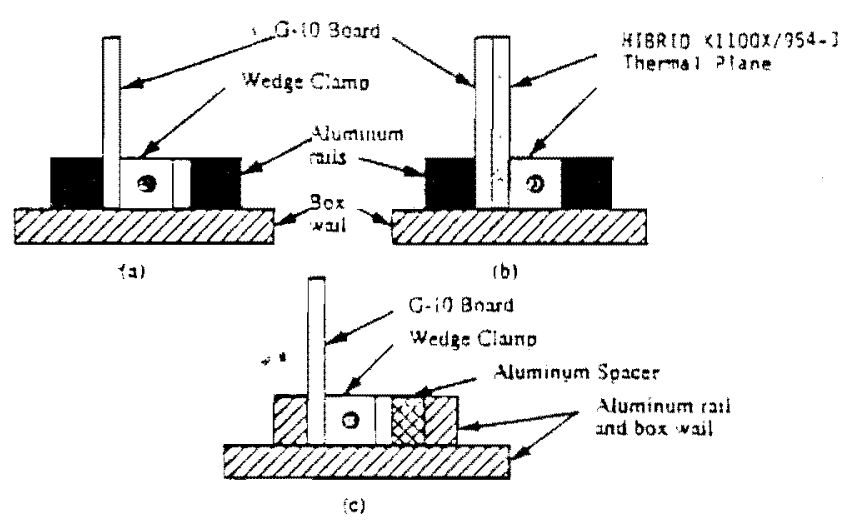

Figures $4 a, 4 b, 4 c$

Table 4 Test Configuration

\begin{tabular}{|c|c|c|c|c|}
\hline \multirow[b]{3}{*}{ TC No. } & \multirow[b]{3}{*}{ Location } & \multicolumn{3}{|c|}{ - Test Configuration } \\
\hline & & Table 4(a) & Table 4(b) & Table 4(c) \\
\hline & & \multicolumn{3}{|c|}{ Temperature, ${ }^{\circ} \mathrm{C}$} \\
\hline 1 & Heat Source & 53.0 & 43.7 & 73.1 \\
\hline 2 & Board & 44.0 & 34.0 & 34.8 \\
\hline 3 & Board & 38.5 & 32.8 & 34. \\
\hline 4 & Board Back & 51.4 & 33.6 & 44.0 \\
\hline 5 & Rail & 30.0 & 29.5 & 27.2 \\
\hline 6 & Inner Wall & 29.6 & 29.1 & - \\
\hline 7 & Rail & 30.1 & 29.4 & 27.2 \\
\hline 8 & inner Wall & 29.6 & 29.1 & 27.2 \\
\hline 9 & Outer Wall & 28.6 & 28.7 & 28.2 \\
\hline 10 & Outer Wall & 28.3 & 28.6 & 28.2 \\
\hline 11 & Outer Wall & 27.8 & 28.0 & 28.3 \\
\hline 12 & Shroud & 26.5 & 26.8 & 25.3 \\
\hline 13 & Heat Source & 53.4 & 44.5 & 72.5 \\
\hline 14 & Baseplate & 25.9 & 25.9 & 25.8 \\
\hline
\end{tabular}

Also of importance is that the PMC cardcage is less than half the weight of a comparably sized lightweight aluminum cardcage and by utilizing the SNAPSAT ${ }^{\top M}$ construction approach this electronic cardcage can be made affordable (especially for high volume procurements).

\section{PMC Isogrid}

Figure 5 was also part of a recent publication referenced above for the electronic cardcage.

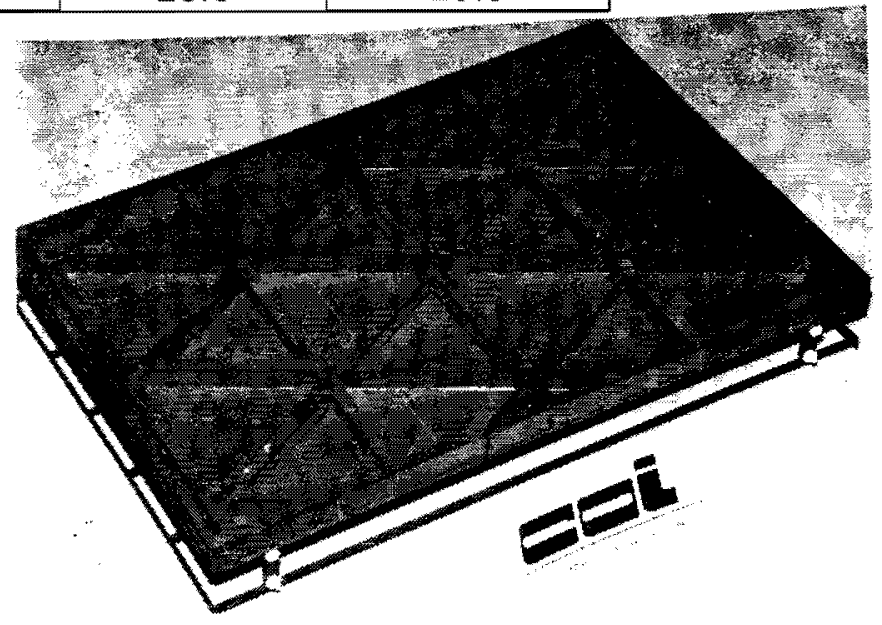

Figure 5 
This isogrid panel illustrates an economical manufacturing method for making SNAPSAT ${ }^{T M}$ isogrid. The variety of applications for this type of structure is potentially unlimited (as are typical honeycomb panels), but at this time these panels have not been structurally or thermally tested. SNAPSAT $^{T M}$ isogrid is a way to provide affordable panel-type structures, especially when compared to aluminum core PMC and skin structures, particularly considering these SNAPSAT ${ }^{T M}$ isogrid features:

- Minimal tooling (self-fixturing)

- Reduced material types (basic panel only involves one material)

- Reduced inspection (fewer processes)

- Less sensitive to damage (thicker skins)

- If damaged, easier to repair

- Reduced schedule, time to produce parts (lends itself to automated manufacturing).

For some applications, this type of structure may be worth considering (over honeycomb) for reasons other than affordability, namely:

- Potential to be more thermally efficient

- Potentially lighter

- Contamination control factors (all surfaces accessible)

- Thermal stability

- Easily integrated into a SNAPSAT ${ }^{\top M}$ type structure

\section{Multi-Functional Structures}

Future satellite structures will surely be smaller (miniature even) and have to provide multifunctional capabilities (e.g., NASA/JPL's New Millennium Program).

Making spacecraft more affordable is the driving factor, primarily to reduce the launch cost by placing more spacecraft in orbit with one launch vehicle, thus dividing the cost of the launch among several spacecraft. Smaller and smaller satellites can result in reduced mission lifecycle cost, with miniaturization playing a larger roll in achieving this goal. It may be necessary for multi-functional structure or "material form" to be made up of pieces (each piece having a different function) and then assembled together to form the spacecraft bus or payload, or both. This modular concept is very attractive, if not essential, for future miniature spacecraft.

The need for these types of affordable spacecraft may be an ideal application for SNAPSAT ${ }^{\top M}$ construction methods.

Figure 7 represents a material form that could be assembled to other similar (but functionally different) material forms that "snap" together, and together, constitute a completed structure.

Some material forms may be highly conductive (thermally), some may be insulated thermally, others may be optical, or support electronics (including integrated circuitry).

Enclosed volumes (after assembly of different modular pieces) may be able to dissipate heat very effectively using these material forms or thermally insulate a piece of equipment in the enclosed space. The entire assembly together may be acceptable as an optical bench or platform.

By using SNAPSAT ${ }^{\text {TM }}$ Technology to fabricate PMC parts with core materials that are highly conductive (e.g., a core of Amoco's K1100X) or very non-conductive (e.g, a core filled with Aerogel), affordable multi-functional structures can be fabricated. 


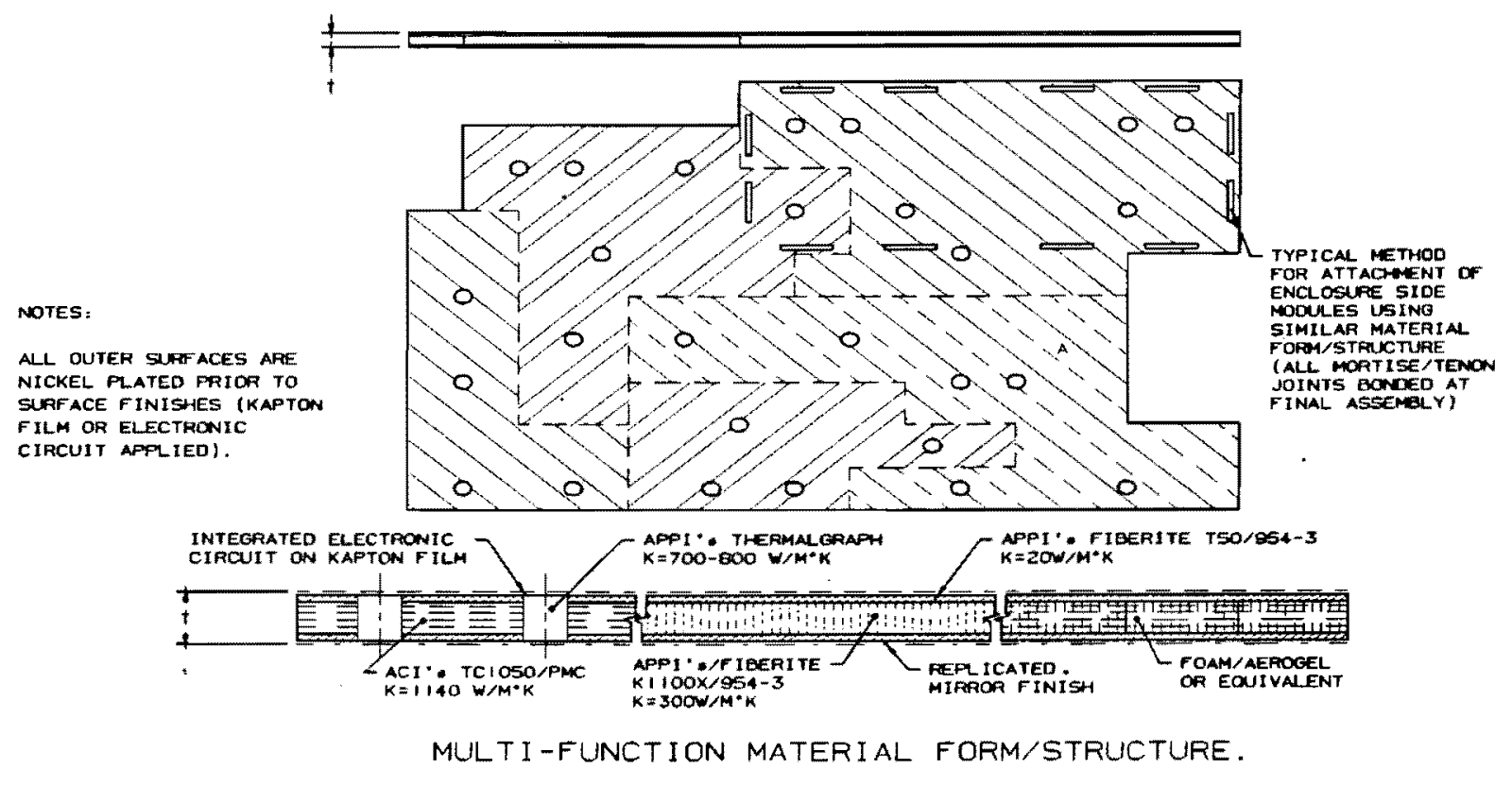

Figure 6

\section{SUMMARY and CONCLUSION}

Any number of material forms are possible for these modular and multi-functional systems, and it is exciting to visualize what future spacecraft will look like. Even more exciting (or challenging) for the structural designer is to visualize how the design/manufacturing approach can be made affordable.

The advanced technologies presented in this paper are intended to enable future spacecraft structural components to be produced in significantly less time, at significantly less cost and, at the same time improve performance. Also, to provide some insight as to how polymer matrix composites will play a roll in the future miniaturization of satellites by virtue of their adaptability to multi-functional structures.

\section{REFERENCES}

1 Krumweide, G.C., Chamberlin, D.N., and Rule, J.E., "Adaptation and Innovation in High-Modulus Graphite/Epoxy Composite Design: Notes on Recent Developments", S.P.I.E., O-E LASE '88, Los Angeles, CA, January, 1988.
2 Brand, R.A., Derby, E.A., "Evaluation of High-Modulus Pitch/Cyanate Material Systems for Dimensionally Stable Structures", Proceedings S.P.I.E. Design of Optical Instruments, Vol. 1690, p309. Orlando, 1992.

3 Krumweide, G.C., "Applications of High Thermally Conductive K1100X/Resin Systems to Spacecraft Structures and Equipment", $1^{\text {sT }}$ Annual Spacecraft Thermal Control Symposium, Albuquerque, N.M., 1995

4 Thompson, T.C., (et al LANL) and Krumweide, G.C. (et al COI) "Development of an All-Composite Spacecraft Bus for Small Satellite Programs", Eighth Annual AIAAVUSU Conference on Small Satellites, Logan, UT, 1994.

5 Grastataro, C.I. (et al ), "Development of a Composite Satellite Structure for FORTE”, ICCM-10, Whistler, B.C., CANADA, August, 1995. 